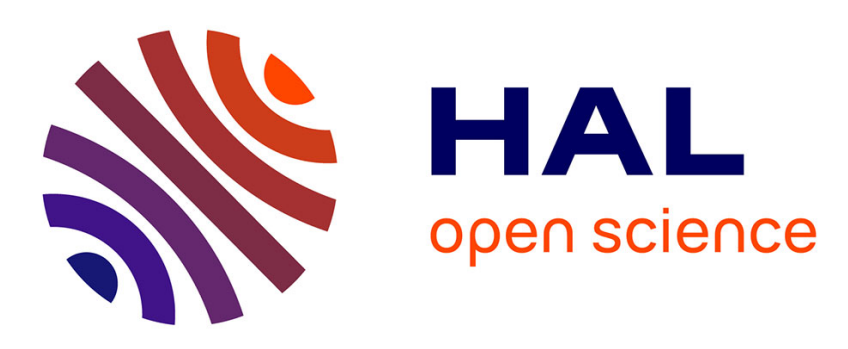

\title{
Unraveling topography around subduction zones from laboratory models
}

Laurent Husson, Benjamin Guillaume, Francesca Funiciello, Claudio Faccenna

\section{To cite this version:}

Laurent Husson, Benjamin Guillaume, Francesca Funiciello, Claudio Faccenna. Unraveling topography around subduction zones from laboratory models. Tectonophysics, 2012, 526-529, pp.5-15. 10.1016/j.tecto.2011.09.001 . insu-00676700

\section{HAL Id: insu-00676700 \\ https://hal-insu.archives-ouvertes.fr/insu-00676700}

Submitted on 8 Mar 2012

HAL is a multi-disciplinary open access archive for the deposit and dissemination of scientific research documents, whether they are published or not. The documents may come from teaching and research institutions in France or abroad, or from public or private research centers.
L'archive ouverte pluridisciplinaire HAL, est destinée au dépôt et à la diffusion de documents scientifiques de niveau recherche, publiés ou non, émanant des établissements d'enseignement et de recherche français ou étrangers, des laboratoires publics ou privés. 


\title{
Unravelling topography around subduction zones from laboratory models
}

\author{
Laurent Husson *,a,b, Benjamin Guillaume ${ }^{\mathrm{c}, \mathrm{d}}$, \\ Francesca Funiciello ${ }^{\mathrm{d}}$ and Claudio Faccenna ${ }^{\mathrm{d}}$
}

\author{
${ }^{a} C N R S$, Géosciences Rennes, Université de Rennes 1, Rennes, France \\ ${ }^{\mathrm{b}}$ CNRS, LPG Nantes, Université de Nantes, Nantes, France \\ ${ }^{\mathrm{c}}$ CNR-Istituto di Geologia Ambientale e Geoingegneria, Rome, Italy \\ dDipartimento di Scienze Geologiche, Università Roma Tre, Rome, Italy
}

\begin{abstract}
The relief around subduction zones results from the interplay of dynamic processes that may locally exceed the (iso)static contributions. The viscous dissipation of the energy in and around subduction zones is capable of generating kilometer scale vertical movements at the surface. In order to evaluate dynamic topography in a self-consistent subduction system, we carried out a set of laboratory experiments, wherein the lithosphere and mantle are simulated by means of newtonian viscous materials, namely silicone putty and glucose syrup. Models are kept in their most simple form and are made of negative buoyancy plates, of variable width and thickness, freely plunging into the syrup. The surface of the model and the top of the slab are scanned in three dimensions. A forebulge systematically emerges from the bending of the viscous plate, adjacent to the trench. With a large wavelength, dynamic pressure offsets the foreside and backside of the slab by $\sim 500 \mathrm{~m}$ on average. The suction, that accompanies the vertical descent of the slab depresses the surface on both sides. At a distance equal to the half-width of the slab, the topographic depression amounts to $\sim 500 \mathrm{~m}$ on average and vanishes at a distance that equals the width of the slab. In order to explore the impact of slab rollback on the topography, the trailing edge of the plates is alternatively fixed to (fixed mode) and freed from (free mode) the end wall of the tank. Both the pressure and suction components of the topography are $\sim 30 \%$ lower in the free mode, indicating that slab rollback
\end{abstract}


fosters the subsidence of upper plates. Our models are compatible with first order observations of the topography around the East Scotia, Tonga, Kermadec and Banda subduction zones.

Key words: subduction, dynamic topography, dynamic pressure, forebulge, analogue modeling

\section{Introduction}

The topography results from a variety of processes that, around subduction zones more than anywhere else, have strong spatial gradients. At the surface of the Earth, the conjunction of these processes not only produces the most important deviations from the geoid (outlined by the $5-10 \mathrm{~km}$ deep trenches), but also the largest topographic slopes, offshore and onshore. The topographic expression of subduction zones is viewed as the juxtaposition of a depressed bathymetry of the overriding plate, a deep trench, an outer rise (or forebulge). This structure correlates well with the gravity signal, in particular long wavelength geoid highs that correspond to the density anomalies of the subducted slabs, overprinted by sharp free air lows over the trenches that highlight the dynamic nature of the topographic depression, and an intermediate scale free air low that highlights the dynamic deflection of the overriding plate $[1-5]$.

In fact, the processes that generate the total relief can be separated into the static components of the relief, that are primarily due to the lateral density variations within the lithosphere, and the more elusive dynamic topography that is, within its common geophysical sense, the response of the surface to the stresses that arise from the underlying mantle flow [6-9]. The process is presumably rather well known in theory, and a vast amount of work has focussed on explaining a variety of transgressive episodes thanks to models of dynamic topography around subduction zones [10-12,5,13-16]. However, the magnitude and wavelength remains highly uncertain (see e.g. Krien and Fleitout [17]). Indeed, even if many of the cited applications are appealing, Wheeler and White [18] conversely found no significant dynamic topography in South East Asia, where it is presumably represented at best, above the largest concentration of slabs at present-day. Uncertainty persists for several reasons.

First, the observation of the topography of the Earth around subduction zones is blurred by the convolution of complex mechanisms, and therefore requires meticulous analysis of, for instance, the admittance of topography and gravity

\footnotetext{
* laurent.husson@univ-rennes1.fr
} 
signals [19]. But only a clear conception of the structure of the lithosphere at a global scale, and at a degree that is almost always beyond our current knowledge, could definitely solve this issue.

Second, confusion may arise from the definition of dynamic topography. In fact, several components of the topography have a dynamic origin, and coining it to the sole contribution of mantle flow underneath the lithosphere is not only restrictive but misleading. In particular around subduction zones, a variety of dynamic processes lead to the formation of, for the most obvious parts, the forebulge and the trench.

Third, a variety of studies have individually explored the different mechanisms, predicting a plausible relief that integrates all such processes is theoretically rendered possible thanks to numerical models, even in three dimensions. However, at this stage, many technical challenges (free surface condition, threedimensional aspect) or mechanical issues (one-sided subductions, trench behavior, etc...) make numerical simulations around subduction zones neither definitive nor consensual. In fact, only few attempts were done to capture all the elements of the topography around subduction zones together $[3,4,20,21]$.

Analogue models may offer an alternative. In this paper, we thus build upon classic analogue models of subduction zones [22-24] to unravel the topography around subduction zones. The following experiments therefore represent a first attempt to model the topography around subduction zones self-consistently, i.e. by examining the case of free subductions, wherein the dynamics is only driven by the buoyancy of the slab and resisted by the viscous flow in the surrounding mantle. Such setting is rendered possible thanks to the advantages of laboratory models.

\section{The models}

\subsection{Experimental setup}

We carried out a set of 13 experiments that essentially reproduce the lines of the experiments of [22] or [24] (Supplemetary material 1). We use silicone putty (Rhodrosil Gomme, PDMS + iron fillers) and glucose syrup to model the lithosphere and the upper mantle, respectively. Silicone putty is a viscoelastic material but its Maxwell time $(<1 \mathrm{~s})$ precludes any elastic behavior in our models lasting several minutes. Glucose syrup is a transparent Newtonian lowviscosity and high-density fluid. These materials have been selected to achieve the standard scaling procedure for stresses scaled down for length, density and 
viscosity in a natural gravity field as described by Weijermars and Schmeling [25] and Davy and Cobbold [26].

The scale factor for length is $1.5 \times 10^{-7}(1 \mathrm{~cm}$ in the experiment corresponds to $66 \mathrm{~km}$ in nature) (Table 1). Densities and viscosities are assumed to be uniform over the thickness of the individual layers and are considered to be averages of the actual values. For the reference model, described hereafter, the negative buoyancy of the lithosphere is $-91 \mathrm{~kg} / \mathrm{m}^{3}$ (Table 1 ). The viscosity ratio between the slab and the surrounding mantle $\left(\eta_{l} / \eta_{m}\right)$ is $1.4 \times 10^{4}$. This value appears to be an upper bound according to recent studies [21,27-30].

\subsection{Experimental procedure}

The system is disposed in a $80 \mathrm{~cm}$ wide square tank (fig. 1). The experimental subduction is always initiated by artificially forcing the leading edge of the silicone plate into the glucose downward to a depth of $3 \mathrm{~cm}$ (corresponding to about $200 \mathrm{~km}$ in nature). We complemented the standard setup [22] by adding a laser scan (put the reference of the old laser? I don't have them) above the tank and digitize the deforming topography. The laser is capable of acquiring the topography with a maximum horizontal resolution of $0.13 \mathrm{~mm}$. The precision of punctual topographic data is $0.05 \mathrm{~mm}$ (this is for new laser), which considerably improves when a statistical treatment is applied. In the following, we refer to the side of the unsubducted portions of the plate as the foreside and conversely, the backside is the region above the sunken slab (fig. 1).

For modeling conveniency, each experiment is separated into two sub-experiments. The first stage of the experiments takes place within the framework of fixed edge subduction sensu Kincaid and Olson [31], i.e. the trailing edge of the slab is attached to the tank in order to preclude any trenchward motion of the silicone plate. When steady state is reached (when the generic $S$ shape of the retreating slab is reached and the geometry remains unchanged in the referential of the moving trench), the shape of the silicone slab is scanned before the surface is spray-painted (in order to overcome optical issues due to the translucency of the glucose syrup) and scanned as well. When all measurements are done, the trailing edge of the silicone slab is freed from the tank, and the subduction enters a free edge mode for a second sub-experiment. Because the surface remains painted from the first stage, it is technically impossible to scan the surface of the slab at depth without strongly damaging the experiment. Only the topography of the surface of the model is thus acquired when a new steady state is reached. 


\subsection{Force balance}

Our simplified subduction system is designed in order to impose a straightforward force balance that approximately reproduces that of plate tectonics: the slab drives the flow in the glucose syrup and is resisted by the viscous dissipation in the glucose syrup and slab. It simply reads $F_{s p}+F_{r p}=F_{v}+F_{b}$, where $F_{s p}$ is the slab pull force, with $F_{s p}=\left(\rho_{l}-\rho_{m}\right) g W z_{s} \frac{H}{\sin \alpha}$, where $g$ is the gravitational acceleration, $H$ and $W$ the thickness and width of the slab, $z_{s}$ the depth of the leading edge of the slab $\left(z_{s}=D\right.$ in steady state, where $D$ is the thickness of the glucose syrup layer), and $\alpha$ the dip of the slab. $F_{r p}=\left(\rho_{l}-\rho_{m}\right) g \frac{H^{2}}{2}$ is the ridge push force, which in the free mode is negligible with respect to the slab pull force [22]. In the fixed subduction mode, the situation differs because of the no motion boundary condition. This kinematic (as opposed to dynamic) condition implies that $F_{r p}$ constantly adjusts to balance the trenchward force that applies to the plate. That force is the opposite of the integral of the trench perpendicular component of the horizontal shear stresses underneath the lithosphere. These stresses result from the underlying viscous flow in the syrup, ultimately excited by the subduction of the slab. Paradoxically in that mode, the sign of $F_{r p}$ implies that, as opposed to the situation on Earth, it is a resisting force.

$F_{b}$ is the bending force of the silicone slab. Funiciello et al. [27] computed the total value of $F_{b}$ by integrating its local values along the bent lithosphere, such that $F_{b}=\int_{i} \frac{2}{3} W \eta_{l} v_{\text {sub }}\left(H_{i} / r_{i}\right)^{3} d i$, where $H_{i}$ is the varying thickness of the slab alongside the slab length and $r_{i}$ is the varying radius of curvature. $\eta_{l}$ is the dynamic viscosity of the silicone putty and $v_{s u b}$ is the subduction velocity. The viscous dissipation due to slab bending in our models (10 to 30\% [27]) is possibly slightly overestimated compared to that of the Earth. First, it is counted twice because the plate bends at the surface, but also at the bottom of the tank, where the slab retrieves a flat, horizontal geometry. In addition, because our slab to mantle viscosity ratios, when scaled to the Earth, are in the high end of the inferred range of values [27,32,30], the bending force may be high. In real Earth, it is now thought that the bending dissipates less than $\sim 25 \%$ of the energy [29], and even more likely between 5 and $20 \%$ [33].

Last, the viscous force $F_{v}$ that stirs the glucose syrup is more difficult to assess; there is no proper analytical solution besides scaling $F_{v}$ with $\eta_{m} v$ (where $v$ is the rate at which the slab rolls back). Indeed, this is particularly unfortunate because that viscous flow is responsible for the long wavelength dynamic distortion of the surface. 


\subsection{Limitations of the model}

Before going further, a few limitations that are intrinsic to our models should be outlined. First of all, the seldom discussed surface tension [34,35] affects the dynamics of our experiments. In a sense, surface tension can conversely be regarded as fortunate, because it coincidentally holds at the surface the silicone plates, whose buoyancies fall within the desired range of exploration, and let them sink beyond. However this is not an Earth-like property and as such it may alter the interpretation of subduction dynamics. In addition, the paint layer may also modify the surface tension of the fluid with respect to the experiments that are exempt of paint. The effect of surface tension is critical only when the slab buoyancy forces are low enough to be comparable to that of surface tension. It could explain the non-linear behaviour of some analogue models. For instance, in the experiments of Schellart [23], subduction kinematics do not scale linearly with slab buoyancy, that is presumably the only varying parameter of the experimental serie. However, such non linearities are not striking in the experiments of Funiciello et al. [22]: during the early stages of subduction, trench retreat rates seemingly increase almost linearly with the slab pull force. Therefore, we assume that the role of surface tension, although non negligible [35], doesn't significantly bias our results, but should be carefully considered when full parametric studies are carried out.

Second, our models have no overriding plates. In precursory models, [36] successfully overcame this issue by adding a viscous upper plate and measuring the elevation changes throughout the experiment. This was suited for their applied experiments, but added some noise to the results. Here instead, as in the seminal experiments of subduction zones [22-24], we simplify the models in order to extract the quintessential processes that shape the surface of the Earth around subduction zones, but also to evaluate the feasibility of such technique from a general standpoint. We are well aware that introducing upper plate changes the subduction dynamics $[17,37,38]$, but a full parametric study, that would explore a variety of boundary conditions (including upper plates) is beyond the scope of this paper.

Third, the tank is not infinite, which often appears satisfying enough for the study of subduction dynamics in general [22-24]. However, given that the very distribution of the stresses within the flowing glucose syrup controls the topography, its perturbation by the non-infinity of the tank plays a role. This imposed condition nevertheless partly compares to real Earth, wherein slabs neither sink into an infinite mantle nor evolve within a domain bounded by undeformable, finite boundaries. This intermediate situation is often misleading when comparing real Earth subduction dynamics to simplified models that display framed isolated systems. 


\section{Results}

All our models follow comparable evolutions. Once steady state is reached, the slab is folded twice, at the surface and at the bottom of the tank, where it literally unfolds. Subduction freely occurs: it is driven by the sole slab buoyancy and resisted by the viscous flow in the glucose syrup. The slab enters a classic rollback subduction mode. The trench therefore retreats while the slab sweeps back into the glucose syrup, which in turn is displaced from the foreside to the backside of the model thanks to a combination of toroidal and poloidal flows [39,40,28] (fig. 2). When it enters the free subduction mode, the plate moves trenchward, therefore reducing the rates of slab rollback $(\sim 12 \%$ for model 1 for instance). The slab consequently becomes steeper. The dynamics of subduction, i.e. the motion of the slab and the viscous flow in the glucose syrup, excited by the very motion of the slab, alter the static force balance and reshape the surface of the Earth. Our models allow to unravel the various components.

\subsection{Departure from isostasy as an indicator of the force balance in the system}

The depth $h$ of the silicone layer relative to the glucose syrup is in principle, in isotatic conditions, determined by the buoyancy of the layer, such that $h=$ $\int_{H} \frac{\rho_{l}-\rho_{m}}{\rho_{m}} d z$, where $\rho_{m}$ and $\rho_{l}$ are the densities of the glucose syrup and of the silicone putty, $H$ being the thickness of the silicone layer. Indeed, unsubducted portions of the slab lay at greater depths than the adjacent glucose syrup. This component dominates at the large scale and explains the first order observation of the topography (figs. 2, 3 and 4). (Note that, unlike the Earth's lithosphere, the silicone layer is not bounded by neighboring plates and therefore elevation decreases stepwise from the adjacent glucose syrup. This discontinuity would cause the silicone plate to subduct if surface tension was not high enough to prevent this from happening, as illustrated by the meniscuses that make the transition from the elevation of the glucose syrup to that of the silicone plate, fig. 4b). Note that this it is not surface tension that plays this role on Earth but the fact that oceanic plates are not in isolation from one another. It is simply the lateral continuity of the lithospheres that prevents the lighter underlying mantle from welling above the plates.

A closer examination of the topography reveals that it departs from isostasy at different spatial scales, that are due to the dynamic evolution of the system. The viscous dissipation of the energy modifies the static equilibrium. It bends the silicone plate, which produces some relief, and stirs the glucose syrup, which also deforms the surface. In the glucose syrup, the viscous dissipation can be separated into the poloidal (in the vertical plane) and toroidal (in 
the horizontal plane) components. The retrograde motion of the slab into the syrup modifies the horizontal stress field and its descent into the fluid induces the vertical one. The convolution of these dynamic processes causes, across subduction zones on Earth, a variety of features that can be deciphered thanks to our integrative experiments.

\subsection{Trench}

The most obvious feature that departs from the static topography is naturally the trench (figs. 3, 4 and 5). Trench depths reach $\sim 3-4 \mathrm{~mm}$ and do not vary significantly from the fixed mode subduction mode to the free mode (fig. 4a). Along-strike (parallel to the trench), the trench is almost uniformly deep; only at very short distances (less than a fifth of the slab width) from the slab edges does it shallow (fig. 3); this highlights that this structure is essentially twodimensional, across strike. In real Earth, the depth of the trench is determined by the shear coupling between the upper and lower plates on the interplate fault $[4,41]$. Our model is purely viscous and there is therefore no proper subduction fault that could be defined by a yield stress. Instead, the depression results from the competition between the buoyancy stresses in the glucose syrup, that tend to restore uniformity, and the shear stresses exerted by the subducting slab that impose the downward flow of the glucose syrup. The main difference is that the flow in the wedge has a boundary condition that is more kinematic, imposed by the subduction rate, than dynamic, i.e. defined by a shear stress. The glucose syrup at the interface therefore must flow along with the subducting plate. Note that part of the apparent trench in our models is a meniscus from surface tension (see above). Scaled to the Earth, predicted trench depths amount to $20-25 \mathrm{~km}$, which seems impressively unrealistic, but is in fact only approximately two to three times larger than actual trenches (after sediments are stripped off).

\subsection{Viscous bulge}

Adjacent to the trench is the forebulge on the silicone plate (figs. 3, 4 and 5). Bulges in our experiments result from the viscous flexure of the silicone plate. Their 0.15 to $0.2 \mathrm{~mm}$ high, $75 \pm 25 \mathrm{~mm}$ wide, elongate bodies lie parallel to the trench, at a distance that varies of $\sim 50 \mathrm{~mm}$ in the free mode and $\sim 44 \mathrm{~mm}$ in the fixed mode. This difference arises from the fact that slabs are steeper in the free mode, a fact that doesn't affect the elevation of the bulge that remains comparable in both cases. This may be explained by the fact that subduction rates play a a fundamental role. Indeed, if the rate of trench retreat is lower of $12 \%$ in the free mode, the subduction rate remains comparable. 
Contrarily to the trench, the bulge reaches its maximum elevation near the edges of the plate, and not in the center (figs. 3 and 5). This observation is somewhat surprising given the fact that the flexure of a viscous plate is $a$ priori a two-dimensional problem and as such, there is no intrinsic reason for the bulge to have its elevation vary along-strike. It results from the interaction with the suction component, which is larger in the center of the slab that at the edges (see section 3.5).

In theory, the viscous flexure of the plate is periodic, and the magnitude of the oscillation diminishes exponentially towards the foreside $[42,43]$. The forebulge should therefore be followed by a deflection, but its magnitude is too small to be detected in our experiment. Not surprisingly, the plate flexure follows the universal deflection profile [42]. Scaled to the Earth, the modeled bulges are 1.0 to $1.3 \mathrm{~km}$ high and $500 \pm 175 \mathrm{~km}$ large. The distance between the maximum elevation of the bulge and the trench varies from $\sim 335 \mathrm{~km}$ to $\sim 300$ $\mathrm{km}$, depending on the mode. Our models here reemphasize the possibility that the observed outer rises are due to the viscous nature of the lithosphere $[43,41]$.

\subsection{Overpressure}

The depth of the silicone plate is systematically offset by $\sim 100 \mu m$, with respect to the theoretical, isostatic depth, when the subduction occurs in a fixed mode, and is $30 \%$ smaller on average in the free subduction mode (fig. 4a). This is a first order response of the topography to the underlying force balance, in the glucose syrup. The retrograde motion of the slab compresses the glucose syrup in the foreside and conversely, extends it in the backside. The situation is somewhat similar to that of a channel flow between the slab itself and the end wall of the tank, such that $\frac{d p}{d y}=12 \eta_{m} \frac{\bar{v}}{L^{2}}$, where $\frac{d p}{d y}$ is the pressure gradient in the channel parallel to the slab, $\eta_{m}$ is the dynamic viscosity of the glucose syrup, $\bar{v}$ is the mean velocity in the channel, and $L$ is the width of the channel. Mass conservation imposes that $\bar{v} L=u \frac{W}{2}$, where $u$ is the horizontal velocity of the slab and $\frac{W}{2}$ is the half width of the slab. The mean pressure in the channel is $\bar{p}=\frac{3}{2} \eta_{m} \frac{u W^{2}}{L^{3}}$. That dynamic pressure is compensated by a mean deflection of the surface that reads

$$
\bar{\delta}_{z}=\frac{3 \eta_{m}}{2 \rho_{m} g} \frac{u W^{2}}{L^{3}} .
$$

$u$ is counted negative on the backside and positive on the foreside, therefore the two effects amplify the total elevation offset between the front and back of the slab, which therefore approximately equals $2 \bar{\delta} z$ (if the slab plunges into the syrup at an equal distance from each end of the tank). It gives a order of magnitude for $2 \bar{\delta}_{z}$ of 5 to $100 \mu m$ depending on the experimental values. The 
scaled magnitude of the offset is thus 35 to $700 \mathrm{~m}$, depending on the forces at play and on the subduction mode. These results are in the lower bound of our observations which reveals that this approximation may not be robust enough to be further developed. In particular, because the finite geometry of the tank in which the channel is embedded is not accounted for, the channel flow analogy does not permit to explain the uplifted topography outside the channel proper, on the glucose syrup adjacent to the slab. It is nevertheless obviously related to the same overpressure induced by the retrograde motion of the slab (fig. 1). Indeed in our models, the overpressure effect occupies the entire surface of the tank. It induces an overall tilt of the surface and is not restricted to the surface of the plate. This figure only partly compares to real Earth where plates do not subduct in bounded domains (but neither sink in an infinite mantle).

Because in the free subduction mode, part of the pressure is released when the slab is free to move trenchward (free subduction), the elevation offset is lower than the offset in the fixed mode (trench migration rates, and therefore pressure, are lower); it then amounts to $\sim 500 \mathrm{~m}$ on average. This can perhaps be more clearly conceived by stating this in a more rigorous way, that reverses causes and consequences: the very reason why trenches roll back at lower rates in the free subduction mode than in the fixed mode is indeed the pressure drop between the fore and backsides of the slab. Overpressure on the foreside, underpressure on the backside partly work to maintain the slab at a central location in the tank. In the particular case where the pressure gradient balances the slab normal component of the slab pull force, no roll back occurs [20]; this situation is never met in our models.

\subsection{Suction}

At second glance, second order deflections burst out: the topography shows a large scale deflection centered on the trench (figs. 2 and 3), the wavelength of which is much larger than that of the trench. This is the dynamic response of the topography to the vertical motion of the slab, a largely debated feature on Earth's subduction zones [3-5,44,18,45]. It is often referred to as dynamic topography, despite the fact that the other topographic features, besides isostasy, are also dynamic in essence. The descent of the slab induces stresses that are compensated by a vertical deflection of the topography $\delta_{z}$, so that $\delta_{z}=\sigma_{z z} / \rho_{m} g$, where $\sigma_{z z}$ is the vertical stress due to the poloidal flow in the glucose syrup. If forms a depression that is visible in both the foreside and backside of the trench (figs 3 and 4). In the fixed subduction mode, the measured magnitude of the deflection in our experiments is around $75 \pm 50$ $\mu m$ at a distance $W / 2$ (half width of the slab) from the trench, depending on the forces in the presence and setting. This corresponds to $500 \pm 330 \mathrm{~m}$ when 
scaled to the Earth. The deflection reaches its largest magnitude in the center, above the slab, and vanishes laterally, both along- and across-strike. The lateral extent of the anomaly is theoretically infinite in a linear viscous flow but visual inspection of our experiments reveal that the magnitude of the dynamic deflection becomes negligible at an approximate distance $W$ from the trench. On the foreside, the dynamic deflection combines with the short-wavelength, large-magnitude features that are the trench itself and the forebulge (fig. 5). Note that it shall not be confused with the secondary harmonic oscillation of the viscous flexure, because the magnitude is incompatible. Typically, the universal deflection curve for a viscous bulging gives a ratio between the magnitudes of the forebulge and of the depression that follows of about 1/100 [43] after [42], which is considerably less than the 20 to $30 \%$ given by the ratio between the elevation of the forebulge and the deflection.

Free subduction mode (fig. 3b) also naturally produces suction, but fixed subduction systems display wider and deeper dynamic deflections than free mode ones by about $30 \%$. The shape of the deflection relates to the distribution of the mass anomalies at depth and therefore to the shape of the slab in our experiments. Because in the free subduction mode, slabs are steeper [22], the mass excess lays, on a map view, closer to the trench. This makes the wavelength of the dynamic deflection shorter. In addition, in the free subduction mode, the total mass is smaller because the slab is steeper, and therefore shorter (total mass varies like $D \sin \alpha$, where $\alpha$ is the slab dip angle). In our experiments, slab dip increases from $\sim 60^{\circ}$ to $\sim 80^{\circ}$ between the fixed and free modes (Ben, can you put in the correct values??. This decreases the total mass anomaly by $\sim 15 \%$, the slab pull by a similar amount and, if the geometry remained the same, the magnitude of the dynamic deflection too. Because the shape of the slab also changes in the experiment, the modification is not linear, and the deflection in the free mode is also sharper.

Dynamic deflections are time-dependent and the successive scans that we performed during the transition from a fixed subduction mode to a free subduction mode are also available. Similarly, we performed some experiments during which the buoyancy of the slab that enters the subduction varies. This also induces transient behaviors. Typically, the slab is made up of a succession of segments of low and high buoyancies (models 12 and 13, see parameters in Supplementary material 1). We monitored the transient topographic response to the dynamics of subduction through time. As expected, low buoyancy segments are accompanied by smaller dynamic deflections than high buoyancy ones, and reciprocally. These transient regimes shall be compared to the geological record around subduction zones. But this step shall not be envisioned before steady regimes are understood and identified on Earth. 


\section{Comparison to the figure of the Earth}

Our simple setup resembles the Earth to some extent. It therefore permits to quantify the relative importance of each of the contributors that shape the figure of the Earth around subduction zones. In fact, a variety of models was formerly designed at the scale of the subduction zone in order to explore the relationships between the slab and dynamic topography. Few of them however challenge the technical issue of incorporating mobile trenches, although it is known to affect the response of the surface topography [20]. Because they generally aim at quantifying dynamic topography of the overriding plate and neglect the subducting plate, most models implicitly ignore the fact that they constantly modify artificially the stress balance in order to maintain a no rollback condition. The consequences of this choice are not trivial : trench motion controls the flow around subduction zones -and therefore the stress regime- to a degree that may have a profound impact on the flow pattern in the wedge [46]. Imposing trench fixity barely resembles Earth-like conditions and in our models, we adopt two alternative settings. The fixed mode considers that the stresses that resist the displacement of the subducting plate are always large enough to oppose any motion. In that case, trench migration rates equal subduction rates. This example is relevant to the Earth in many instances. For instance, the small-scale subduction zones that are embedded into bigger systems (like the fast Hellenic subduction zone within the slow Africa-Eurasia convergent system, or the East Scotia subduction zone within the South Atlantic). The free subduction mode instead assumes that plate motion is dictated by the force balance at the subduction zone itself. This mode could correspond to any larger subduction system (for instance, NazcaSouth America) under the heavy assumption that the upper plate doesn't play a crucial role in the force balance. In our experiments, fixed subduction systems display wider and deeper dynamic deflections than free mode ones. Such result is beyond what could be inferred by a comparison between the Nazca and Hellenic subduction zones; in that sense, analogue models are helpful to overcome observational issues.

The forebulge is a commonly described feature and it is no surprise that it is well reproduced by our models. As opposed to the more popular elastic bulge $[2,42,47]$, our models predict that outer rises emerge from the flexure of viscous slabs. This idea is however not new: similar geometries have been reproduced with either viscous or elastic rheologies [43], or even with composite rheologies $[48,49]$. However, given the fact that subducting slabs are dominantly treated with viscous rheologies in the litterature, it is good to recall that outer rises may be caused by a process that consistently obeys the same rules. Our models, as many others, is capable of predicting the variable geometry of outer rises to a degree that exceeds observations. In fact, flexure models became popular although they mostly apply to the Aleutian, Kuril, Bonin, and Mariana, i.e. 
a selection of well-behaved subduction zones that were chosen as early as the 70 's to illustrate the theory [2]. Herein we wish to emphasize that, more than the forebulge, that almost only depends on the rheology of the subducting plate, or even the trench, it is the surface expression of the underlying viscous flow that those experiments reveal with a new light.

Interestingly enough, the suction deflection appears on both the back and fore sides of the trench. Global models that are buoyancy driven $[7-9,16]$ also show this, because slabs are the prominent features in the Earth's mantle. But again, models that are designed to investigate the relationships between the subducting slab and the dynamic deflection of the upper plate do not consider the dynamic topography on subducting plates but only focus on upper plates. Our models show that subducting plates (foreside of our models) can also be deflected downward by the suction effect of the underlying mantle flow, by a comparable amount. The signal is not straightforward though, because although it is of opposed sign, this depression competes with the uplift due to the overpressure underneath the foreside of the slab. Therefore, the net result is a global uplift of the foreside, only modulated by the shorter wavelength suction topography (fig. 5). The overpressure effect is expected to uplift the subducting plate at a regional scale by 100 to $600 \mathrm{~m}$. Only at short distance from the trench, this effect should be counterbalanced by the opposite effect of the suction.

In real Earth, the signal is often too blurred to detect the competition between the two processes. It is nevertheless true that the bathymetry, to the East of the East Scotia subduction zone is $\sim 5000 \mathrm{~m}$ deep (fig. 6a), almost $1000 \mathrm{~m}$ deeper than the surrounding portions of the Atlantic plate of similar age. The Tonga and Kermadec subduction zones (considered as two different subduction zones separated by a slab tear from one another at the junction with the Louisville ridge) display comparable relief: the seafloor to the East of the Tonga trench (fig. 6b) lies at $\sim 6000 \mathrm{~m}$, and to the East of the Kermadec trench at $5800 \mathrm{~m}$ (fig. 6b). In all three cases, the seafloor lies 500 to $1000 \mathrm{~m}$ lower (avoiding seamounts) than the surrounding portions of the oceanic plate of similar age. The distance at which the depression becomes insignificant is comparable to the width of the trench, which is remarkably corroborating the suction effect observed in our experiments. In addition, these depressed areas are possibly embedded in wider zones that are themselves possibly at higher elevations than more distal portions of seafloor of similar age. The ages of the foresides of the East Scotia Sea is 30 to $50 \mathrm{Ma}$, that of Tonga is 90 to 100 Ma, and that of Kermadec is 90 to 120 Ma. The expected depth, compared to the mean depths on Earth [50] are respectively $4800 \pm 400 \mathrm{~m}, 5400 \pm 400 \mathrm{~m}$, and $5500 \pm 400 \mathrm{~m}$. The seafloor, in all three cases is 200 to $600 \mathrm{~m}$ shallower than the mean values for the Earth, which is in turn comparable to the prediction of the overpressure effect from our experiments (the observed offset is 
$\bar{\delta}_{z}$, not $2 \bar{\delta}_{z}$ because only the overpressure on the foreside is measured). Last, the inferred suction effect in the Tonga subduction zone is more pronounced, by $\sim 200 \mathrm{~m}$, than in the adjacent Kermadec subduction zone. The subducing plate in the Tonga and Kermadec subduction zones is presumably comparable for it has the same nature. The only a priori differences between the two are (i) a slightly older subducting slab in the South (Kermadec) than in the North (Tonga), which should a contrario enhance the suction effect because of the higher negative buoyancy, and (ii) a much faster slab rollback in the North than in the South. The latter effect efficiently shapes the bathymetry: while the Kermadec trench remains approximately stationary, the Tonga trench is the fastest retreating trench on Earth, at about $160 \mathrm{~mm} / \mathrm{yr}$. This observation supports our model results, which suggest that rollback fosters dynamic topography: dynamic deflections of the topography in the free subduction mode are lower by $\sim 30 \%$ than in the fixed mode. Similar conclusions where reached by Russo and Silver [51], who envisioned the possibility that the shallow Nazca plate could be uplifted by the underlying dynamic overpressure. These observations certainly plead for the existence of dynamic deflection of the foreside of the subduction zones too, but making the link between the two requires a thorough analysis of the bathymetry and gravity.

On the backside however, the effects of dynamic pressure and suction have the same polarity; the cumulated depression predicted by our models thus amounts to $1200 \pm 500 \mathrm{~m}$. At large distances from the trench, only the underpressure effect remains significant, with a downlift of 100 to $600 \mathrm{~m}$. Many examples in continental domains $[12-15,36,52,53]$ display geological signatures that confirm that upper plates are deflected by comparable magnitudes and wavelengths. The long wavelengths of the afore cited examples highlight the importance of the underpressure effect in continental inundation more than that of the suction effect.

In oceanic domains, the underpressure effect on the backside is mode difficult to track on Earth because few subduction zones display clear enough settings. The few candidates are the Philippine plate (40-50 Ma) and the South Fidji basin (20-30 Ma), that respectively lay at $\sim 5900 \mathrm{~m}$ and $\sim 4500 \mathrm{~m}$. Their depths are thus respectively $\sim 1000 \mathrm{~m}$ and $\sim 300 \mathrm{~m}$ deeper than the mean average depth for seafloor of similar ages [50], which again pleads for a deflection that is at least compatible with our model results. The suction effect on the backside is more clearly expressed in oceanic domains. At short distances from its trench, the $8000 \mathrm{~m}$ deep Weber trough in the Banda Sea (fig. 7a) represents, in spite of its extremely young age ( $<3$ Myrs), the deepest seafloor on Earth besides trenches at present-day. It is more than $5000 \mathrm{~m}$ deeper than the mean depth of oceanic units of similar age. Similarly, the residual topography of the East Scotia sea back arc basin (fig. 7, modified after [5]) is deflected towards its center by up to $1500 \mathrm{~m}$ at a short distance from the trench. Both examples confirm that the suction effect of the underlying subducting slabs on Earth 
on upper plates is extremely efficient, in agreement with our models.

The topography in our models emerges from the stress balance and our scanning device allows for a three-dimensional illustration of it. Four dimensional if one accounts for its time evolution. The results often go beyond observational possibilities, and as such they are potentially useful. These tests revealed that analogue models are capable of predicting the evolution of the topography around subduction zones. Specifically, they meet the following criteria: they have free surfaces, they are three dimensional, subduction process is purely dynamic (no kinematic boundary condition), rollback freely occurs. This delicate blend of conditions that are each individually still challenging to model numerically makes our analogue models of use for the analysis and comprehension of the dynamics of relief. Last, these models give a simple view of the three dimensional nature of the topography around subduction zones by combining most processes that deform the surface of the Earth, but nevertheless leave the possibility to extract each component independently, something that is rendered difficult in real Earth, because of the uncertainty in the structure of the lithosphere. 


\section{References}

[1] W. J. Morgan, Gravity Anomalies and Convection Currents, 1, A Sphere and Cylinder Sinking beneath the Surface of a Viscous Fluid, Journal of Geophysical Research 70 (1965) 6175-6187.

[2] A. B. Watts, M. Talwani, Gravity Anomalies Seaward of Deep-Sea Trenches and their Tectonic Implications, Geophysical Journal International 36 (1974) $57-90$.

[3] H. J. Melosh, A. Raefsky, The dynamical origin of subduction zone topography, Geophysical Journal 60 (1980) 333-354.

[4] S. Zhong, M. Gurnis, Viscous flow model of a subduction zone with a faulted lithosphere: Long and short wavelength topography, gravity and geoid, Geophysical Research Letters 19 (1992) 1891-1894.

[5] L. Husson, Dynamic topography above retreating subduction zones, Geology 34 (2006) $741-+$.

[6] P. Colin, L. Fleitout, Topography of the ocean floor: Thermal evolution of the lithosphere and interaction of deep mantle heterogeneities with the lithosphere, Geophysical Research Letters 17 (1990) 1961-1964.

[7] O. Čadek, L. Fleitout, Effect of lateral viscosity variations in the top $300 \mathrm{~km}$ on the geoid and dynamic topography, Geophysical Journal International 152 (2003) 566-580.

[8] R. Moucha, A. M. Forte, J. X. Mitrovica, D. B. Rowley, S. Quéré, N. A. Simmons, S. P. Grand, Dynamic topography and long-term sea-level variations: There is no such thing as a stable continental platform, Earth and Planetary Science Letters 271 (2008) 101-108.

[9] C. P. Conrad, L. Husson, Influence of dynamic topography on sea level and its rate of change, Lithosphere 1 (2) (2009) 110-120.

[10] M. Gurnis, Ridge spreading, subduction, and sea level fluctuations, Science 250 (1990) 970-972.

[11] M. Gurnis, Rapid Continental Subsidence Following the Initiation and Evolution of Subduction, Science 255 (1992) 1556-1558.

[12] J. Mitrovica, The devonian to permian sedimentation of the Russian Platform: An example of subduction-controlled long-wavelength tilting of continents, Journal of Geodynamics 22 (1996) 79-96.

[13] L. Liu, S. Spasojević, M. Gurnis, Reconstructing Farallon Plate Subduction Beneath North America Back to the Late Cretaceous, Science 322 (2008) 934-.

[14] S. Spasojevic, L. Liu, M. Gurnis, Adjoint models of mantle convection with seismic, plate motion, and stratigraphic constraints: North America since the Late Cretaceous, Geochemistry, Geophysics, Geosystems 10 (2009) 5-+. 
[15] C. Faccenna, T. W. Becker, Shaping mobile belts by small-scale convection, Nature465 (2010) 602-605.

[16] L. Boschi, C. Faccenna, T. W. Becker, Mantle structure and dynamic topography in the Mediterranean Basin, Geophys. Res. Lett.37 (2010) 20303-+.

[17] Y. Krien, L. Fleitout, Gravity above subduction zones and forces controlling plate motions, Journal of Geophysical Research (Solid Earth) 113 (2008) 9407+ .

[18] P. Wheeler, N. White, Quest for dynamic topography: Observations from Southeast Asia, Geology 28 (2000) 963-+.

[19] M. I. Billen, M. Gurnis, Constraints on subducting plate strength within the Kermadec trench, Journal of Geophysical Research (Solid Earth) 110 (2005) $5407-+$.

[20] S. J. H. Buiter, R. Govers, M. J. R. Wortel, A modelling study of vertical surface displacements at convergent plate margins, Geophysical Journal International 147 (2001) 415-427.

[21] M. I. Billen, M. Gurnis, M. Simons, Multiscale dynamics of the Tonga-Kermadec subduction zone, Geophysical Journal International 153 (2003) 359-388.

[22] F. Funiciello, C. Faccenna, D. Giardini, K. Regenauer-Lieb, Dynamics of retreating slabs: 2. Insights from three-dimensional laboratory experiments, Journal of Geophysical Research 108 (2003) 2207-+.

[23] W. P. Schellart, Kinematics of subduction and subduction-induced flow in the upper mantle, Journal of Geophysical Research 109 (2004) 7401-+.

[24] N. Bellahsen, C. Faccenna, F. Funiciello, Dynamics of subduction and plate motion in laboratory experiments: Insights into the "plate tectonics" behavior of the Earth, Journal of Geophysical Research (Solid Earth) 110 (2005) 1401-+.

[25] R. Weijermars, H. Schmeling, Scaling of Newtonian and non Newtonian fluid dynamics without inertia for quantitative modelling of rock flow due to gravity (including the concept of rheological similarity), Physics of the Earth and Planetary Interiors 43 (1986) 316-330.

[26] P. Davy, P. R. Cobbold, Experiments of a 4-layered continental lithosphere, Tectonophysics 188 (1991) 1-25.

[27] F. Funiciello, C. Faccenna, A. Heuret, S. Lallemand, E. di Giuseppe, T. W. Becker, Trench migration, net rotation and slab mantle coupling, Earth and Planetary Science Letters 271 (2008) 233-240.

[28] W. P. Schellart, Kinematics and flow patterns in deep mantle and upper mantle subduction models: Influence of the mantle depth and slab to mantle viscosity ratio, Geochemistry, Geophysics, Geosystems 9 (2008) 3014-+. 
[29] B. Wu, C. P. Conrad, A. Heuret, C. Lithgow-Bertelloni, S. Lallemand, Reconciling strong slab pull and weak plate bending: The plate motion constraint on the strength of mantle slabs, Earth and Planetary Science Letters 272 (2008) 412-421.

[30] C. Loiselet, L. Husson, J. Braun, From longitudinal slab curvature to slab rheology, Geology 37 (8) (2009) 747-750.

[31] C. Kincaid, P. Olson, An experimental study of subduction and slab migration, J. Geophys. Res.92 (1987) 13832-13840.

[32] W. P. Schellart, Evolution of the slab bending radius and the bending dissipation in three-dimensional subduction models with a variable slab to upper mantle viscosity ratio, Earth and Planetary Science Letters 288 (2009) 309-319.

[33] G. Stadler, M. Gurnis, C. Burstedde, L. C. Wilcox, L. Alisic, O. Ghattas, The Dynamics of Plate Tectonics and Mantle Flow: From Local to Global Scales, Science 329 (2010) 1033-.

[34] W. Jacoby, Paraffin model experiment of plate tectonics, Tectonophysics 35 (1976) 103-113.

[35] N. M. Ribe, Bending mechanics and mode selection in free subduction: a thinsheet analysis, Geophysical Journal International 180 (2010) 559-576.

[36] B. Guillaume, J. Martinod, L. Husson, M. Roddaz, R. Riquelme, Neogene uplift of central eastern Patagonia: Dynamic response to active spreading ridge subduction?, Tectonics 28 (2009) C2009+.

[37] P. Yamato, L. Husson, J. Braun, C. Loiselet, C. Thieulot, Influence of surrounding plates on 3D subduction dynamics, Geophys. Res. Lett.36 (2009) $7303-+$.

[38] F. A. Capitanio, D. R. Stegman, L. N. Moresi, W. Sharples, Upper plate controls on deep subduction, trench migrations and deformations at convergent margins, Tectonophysics 483 (2010) 80-92.

[39] C. Piromallo, T. W. Becker, F. Funiciello, C. Faccenna, Three-dimensional instantaneous mantle flow induced by subduction, Geophys. Res. Lett.33 (2006) $8304-+$.

[40] F. Funiciello, M. Moroni, C. Piromallo, C. Faccenna, A. Cenedese, H. A. Bui, Mapping mantle flow during retreating subduction: Laboratory models analyzed by feature tracking, Journal of Geophysical Research (Solid Earth) 111 (2006) $3402-+$.

[41] S. Zhong, M. Gurnis, Controls on trench topography from dynamic models of subducted slabs, J. Geophys. Res.99 (1994) 15683-+.

[42] J. G. Caldwell, W. F. Haxby, D. E. Karig, D. L. Turcotte, On the applicability of a universal elastic trench profile, Earth and Planetary Science Letters 31 (1976) 239-246. 
[43] J. De Bremaecker, Is the oceanic lithosphere elastic or viscous?, Journal of Geophysical Research 82 (1977) 2001-2004.

[44] M. Gurnis, Plate-mantle coupling and continental flooding, Geophysical Research Letters 17 (1990) 623-626.

[45] L. Husson, C. P. Conrad, Tectonic velocities, dynamic topography, and relative sea level, Geophys. Res. Lett.33 (2006) 18303-+.

[46] L. Husson, J. Brun, P. Yamato, C. Faccenna, Episodic slab rollback fosters exhumation of HP-UHP rocks, Geophysical Journal International 179 (2009) $1292-1300$.

[47] B. Parsons, P. Molnar, The Origin of Outer Topographic Rises Associated with Trenches, Geophysical Journal International 45 (1976) 707-712.

[48] R. I. Walcott, Flexural Rigidity, Thickness, and Viscosity of the Lithosphere, J. Geophys. Res.75 (1970) 3941-3954.

[49] H. J. Melosh, Dynamic support of the outer rise, Geophys. Res. Lett.5 (1978) $321-324$.

[50] T. Korenaga, J. Korenaga, Subsidence of normal oceanic lithosphere, apparent thermal expansivity, and seafloor flattening, Earth and Planetary Science Letters 268 (2008) 41-51.

[51] R. M. Russo, P. G. Silver, Trench-Parallel Flow Beneath the Nazca Plate from Seismic Anisotropy, Science 263 (1994) 1105-1111.

[52] F. M. Davila, C. Lithgow-Bertelloni, M. Gimenez, Tectonic and dynamic controls on the topography and subsidence of the Argentine Pampas: the role of the flat slab, Earth and Planetary Science Letters 295 (2010) 187-194.

[53] J. Braun, The many surface expressions of mantle dynamics, Nature Geoscience 3 (12) (2010) 825-833.

[54] R. D. Müller, M. Sdrolias, C. Gaina, W. R. Roest, Age, spreading rates, and spreading asymmetry of the world's ocean crust, Geochemistry, Geophysics, Geosystems 9 (2008) 4006--+. 


\begin{tabular}{|c|c|c|c|c|}
\hline \multicolumn{3}{|c|}{ Parameters } & Nature & \multirow{2}{*}{$\begin{array}{c}\text { Reference model } \\
9.81\end{array}$} \\
\hline$g$ & Gravitational acceleration & $m / s^{2}$ & 9.81 & \\
\hline \multicolumn{5}{|l|}{ Length } \\
\hline$W$ & Subducting plate width & $m$ & 990000 & 0.15 \\
\hline$H$ & Subducting plate thickness & & 100000 & 0.0152 \\
\hline$D$ & Upper mantle thickness & & 660000 & 0.10 \\
\hline & Scale factor for length & & \multicolumn{2}{|c|}{$L_{\text {model }} / L_{\text {nature }}=1.52 \times 10^{-7}$} \\
\hline \multicolumn{5}{|c|}{ Buoyancy } \\
\hline \multirow[t]{3}{*}{$\rho_{m}-\rho_{l}$} & Subducting oceanic plate & $\mathrm{kg} / \mathrm{m}^{3}$ & -80 & -91 \\
\hline & & & \multicolumn{2}{|c|}{ (80 Myr-old plate) } \\
\hline & Scale factor for buoyancy & & \multicolumn{2}{|c|}{$\Delta \rho_{\text {model }} / \Delta \rho_{\text {nature }} \simeq 1$} \\
\hline \multicolumn{5}{|c|}{ Viscosity } \\
\hline$\eta_{l}$ & Subducting oceanic plate & Pas & $1.4 \times 10^{24}$ & $4.2 \times 10^{5}$ \\
\hline$\eta_{m}$ & Upper mantle & & $10^{20}$ & 30 \\
\hline & Scale factor for viscosity & & \multicolumn{2}{|c|}{$\eta_{\text {model }} / \eta_{\text {nature }}=3 \times 10^{-19}$} \\
\hline \multicolumn{5}{|c|}{ Characteristic time } \\
\hline$t$ & $t_{\text {nature }} / t_{\text {model }}=\left((\Delta \rho g H)_{\text {model }} /(\Delta \rho g H)_{\text {nature }}\right) \times\left(\eta_{\text {nature }} / \eta_{\text {model }}\right)$ & $s$ & $3.16 \times 10^{13}(1 \mathrm{Myr})$ & 55 \\
\hline & Scale factor for time & & \multicolumn{2}{|c|}{$t_{\text {model }} / t_{\text {nature }}=1.74 \times 10^{-12}$} \\
\hline
\end{tabular}

Table 1

Scaling of the modeling parameters in nature and in the laboratory, for the reference model. 


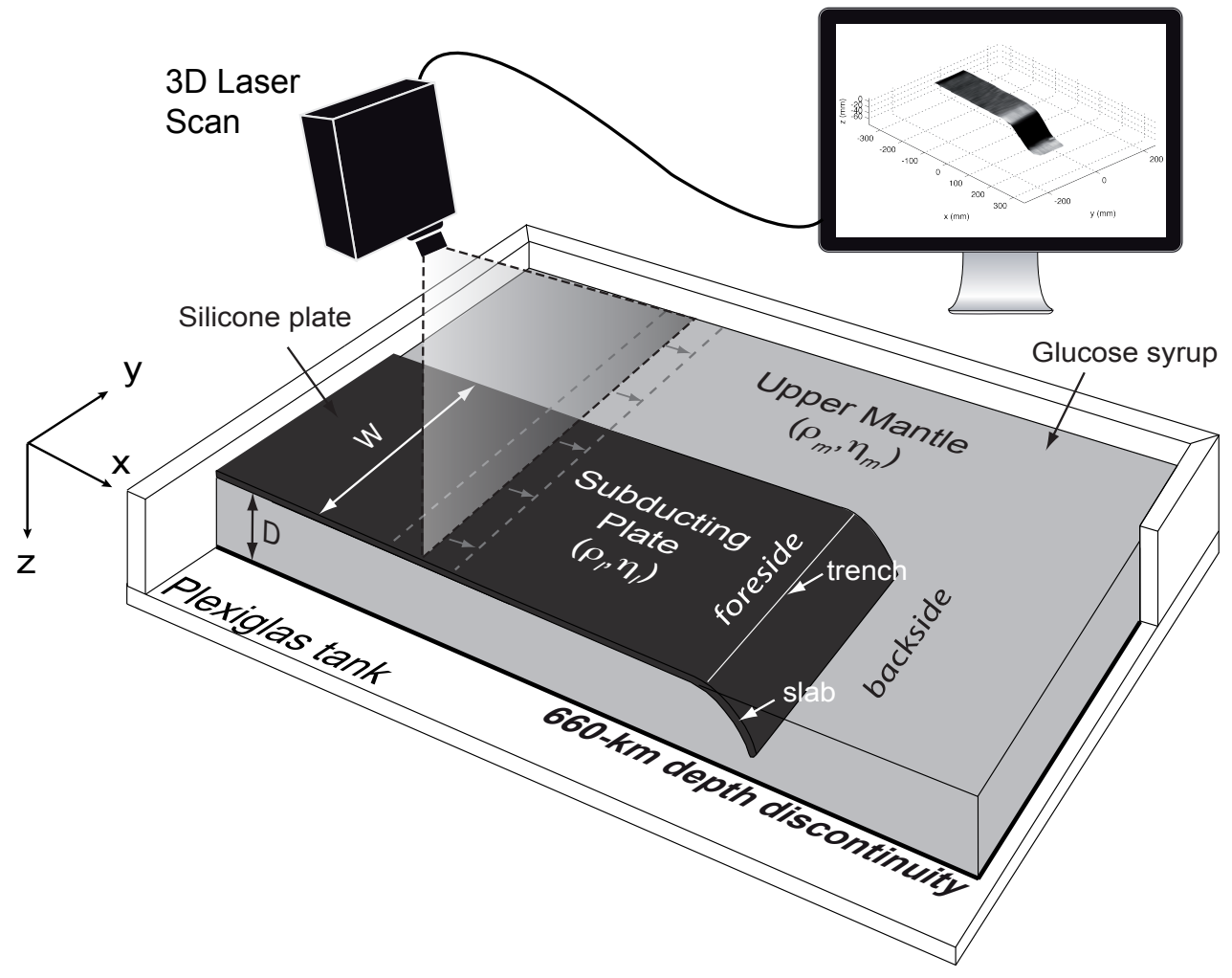

Fig. 1. Experimental setup. The subducting lithosphere is modeled by a silicone plate of density $\rho_{l}$, viscosity $\eta_{l}$, width $W$, thickness $H$. The mantle is simulated by means of glucose syrup of density $\rho_{m}$, viscosity $\eta_{m}$ and thickness $D$. The plate is either fixed, i.e. the trailing edge is attached to the end of the tanks or free, i.e. the trailing edge freely moves. The surface topography in the experiments is monitored by a $3 \mathrm{D}$ laser scanner. The foreside corresponds to the region where the lithosphere has not yet been subducted and the backside is located above the sunken slab. 

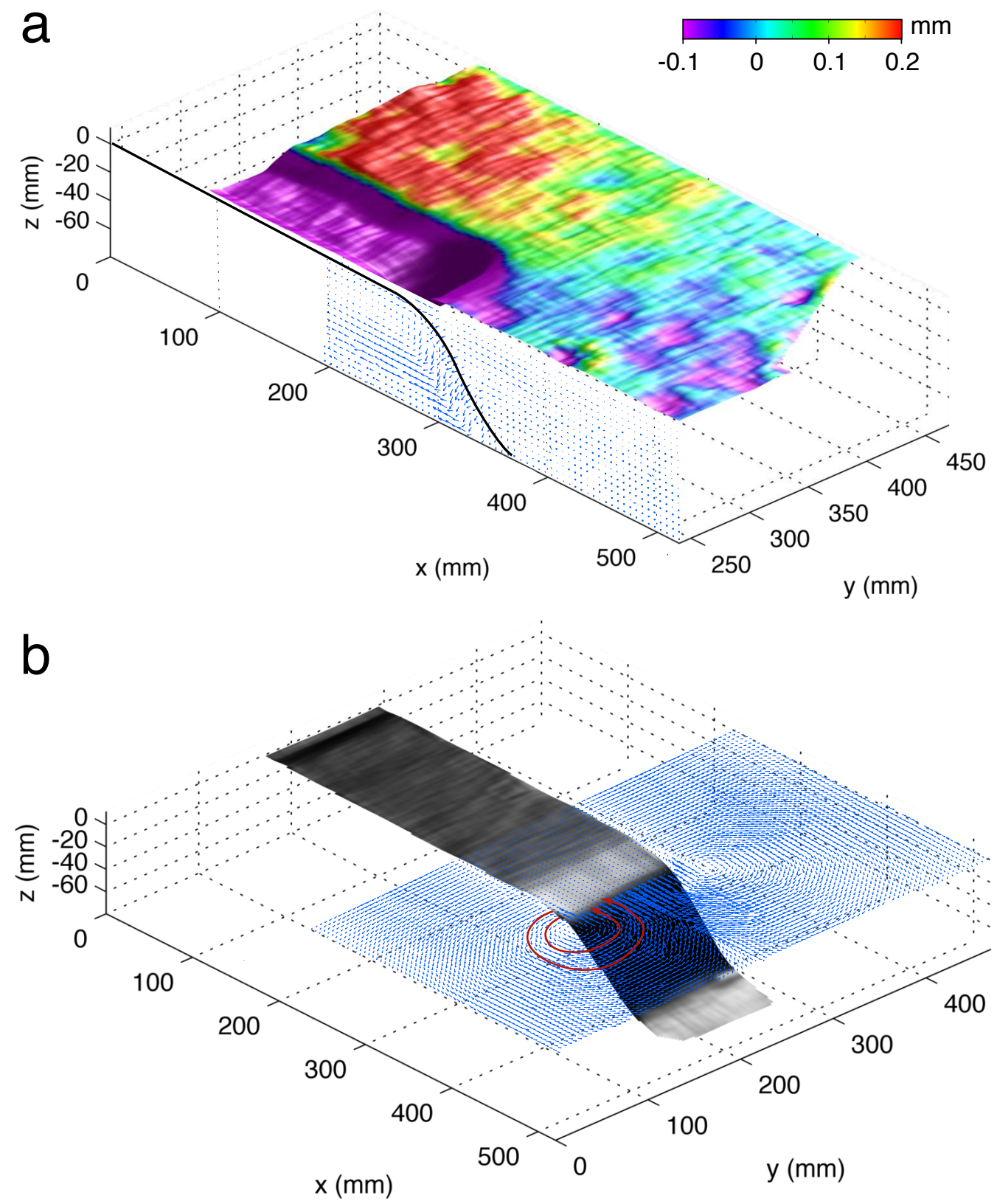

Fig. 2. (a) 3D view of the surface topography (color coded and magnified by a factor 10) cut along the plate centerline and velocity vectors (in blue) of the mantle flow in the vertical section $(x-z)$ for our reference experiment with fixed edge conditions (model 1, see parameters in Table 1). (b) 3D view of the top of the slab shape (in black) and velocity vectors (in blue) of the mantle flow in the horizontal section $(x-y)$ at the top of the mantle for the same model. 

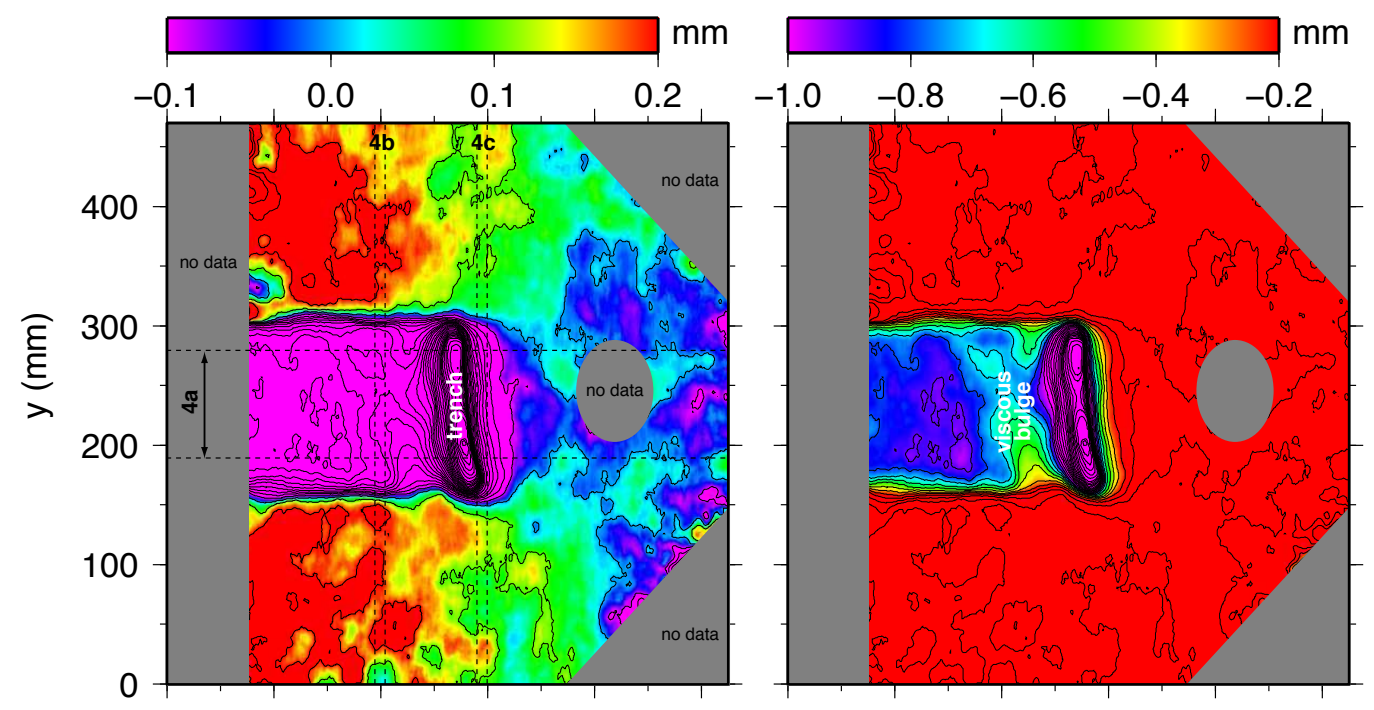

a) fixed edge mode
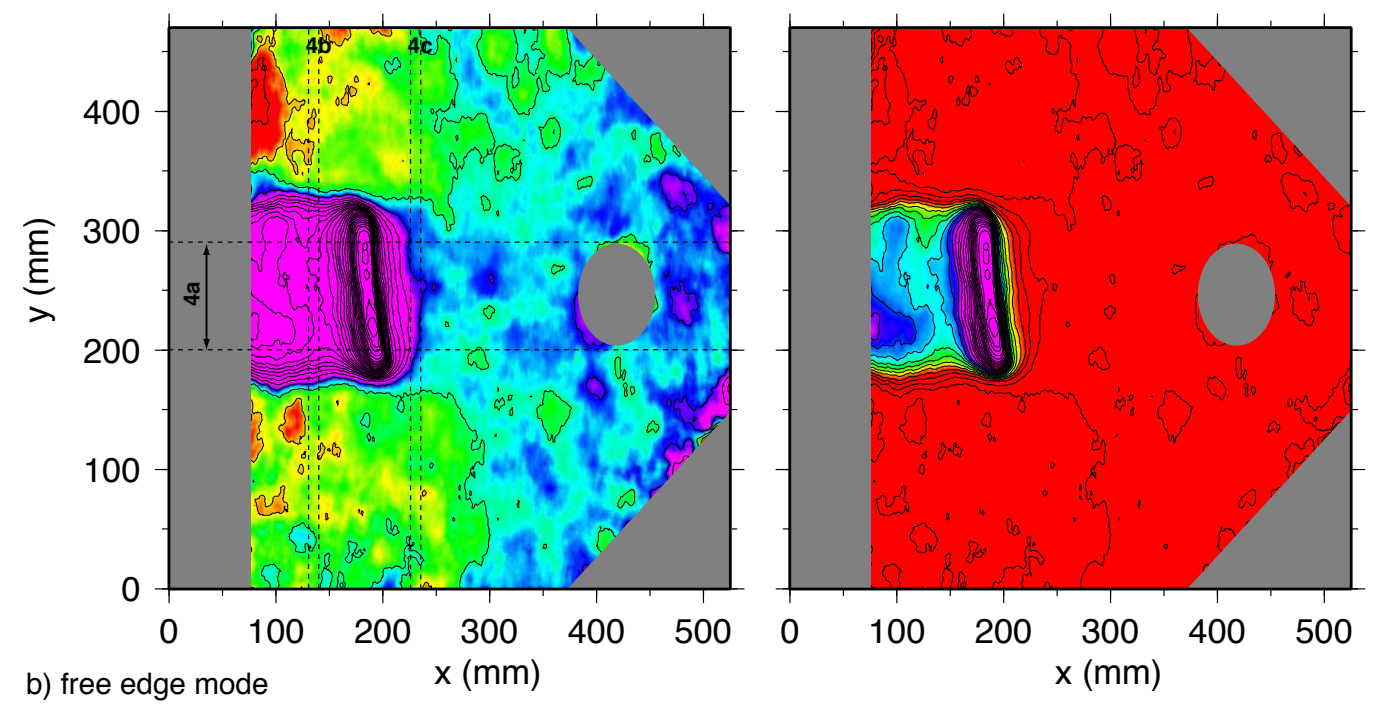

Fig. 3. Map view of the surface of model 1 in the fixed (a) and free (b) subduction modes. Right and left panels display the same maps but with different color palettes in order to respectively highlight the topography of the plate (right) and glucose syrup (left). The dotted lines show the location of the different swath profiles plotted in fig. 4. Areas with no topographic data are indicated in gray. 
a) trench-perpendicular

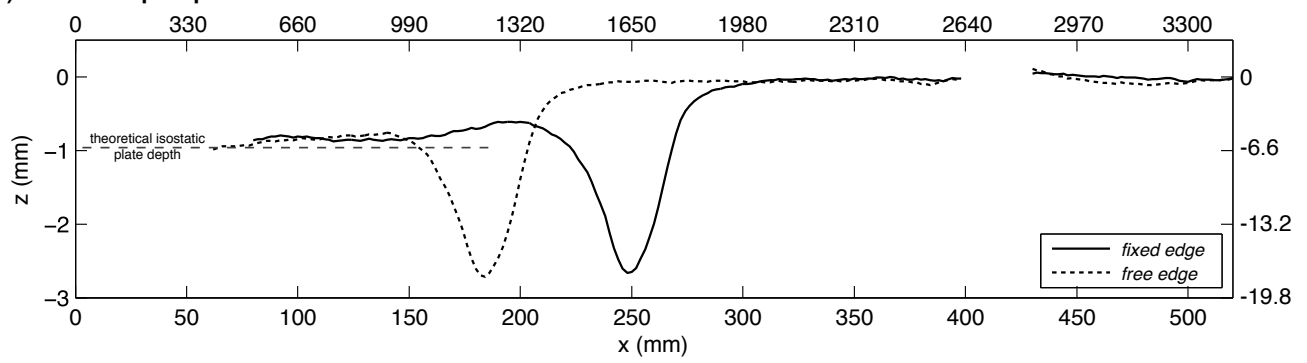

b) trench-parallel (foreside)

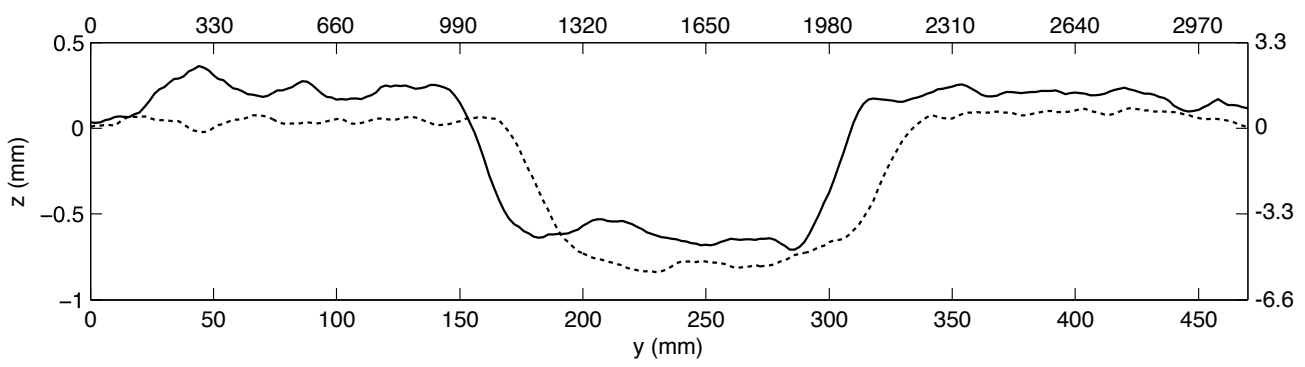

c) trench-parallel (backside) $\quad \mathrm{y}(\mathrm{km})$

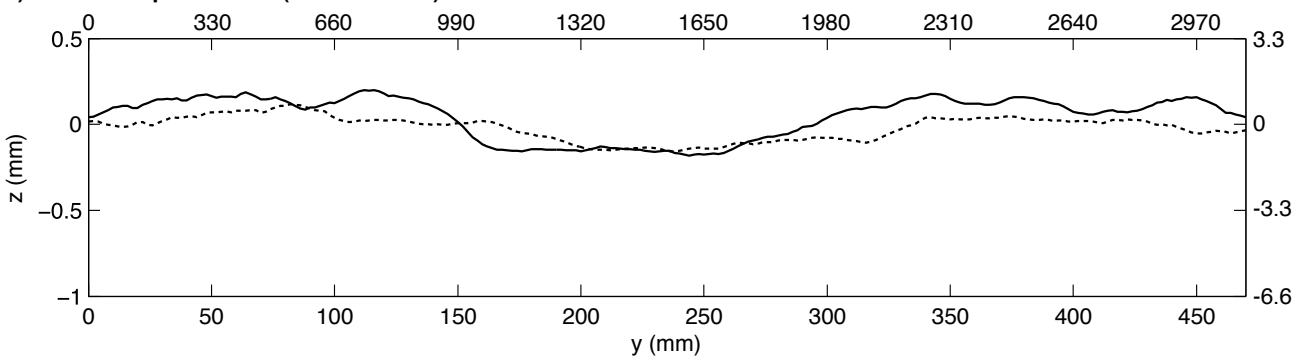

Fig. 4. Swath topographic profiles for model 1 in the fixed (solid line) and free (dotted line) subduction modes (a) in the trench-normal direction, averaged over a distance of $40 \mathrm{~mm}$ from the plate centerline, (b) in the trench-parallel direction in the foreside (50 $\mathrm{mm}$ from the trench), and (c) in the trench-parallel direction in the backside (50 $\mathrm{mm}$ from the trench). Note the different scales for fig. 4a and figs. 4b-c. See fig. 3 for sections location. The theoretical isostatic depth for the plate is indicated by a dashed line in the first panel. 


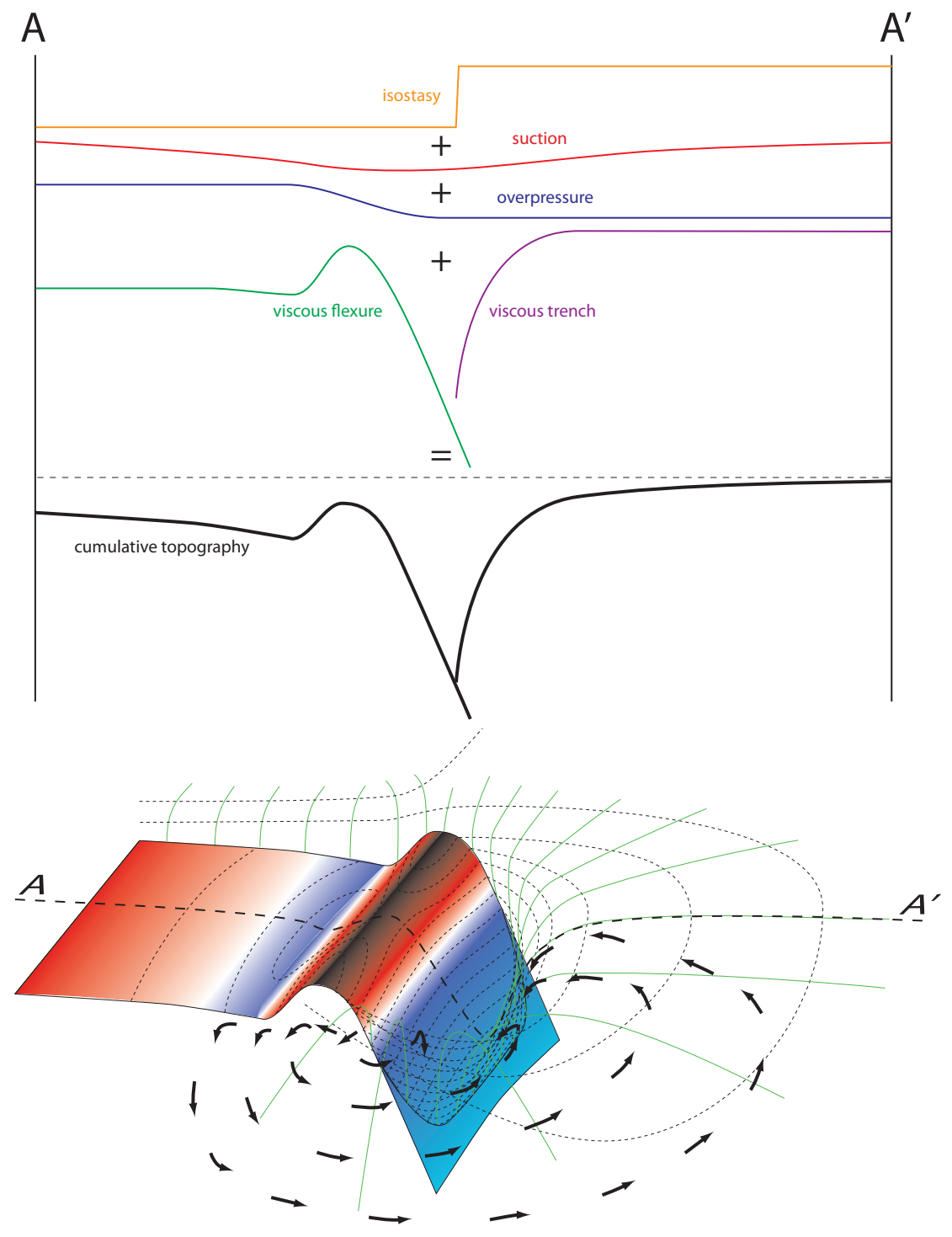

Fig. 5. Synthetic 3D sketch of the topography around a subduction zone (bottom) in the experiments (not to scale). Black dotted lines are isodepths curves, green curves follow the local maximum topographic gradients. Black arrows denote the flow pattern from below the slab on the foreside to above the slab on the backside. Top graph shows the isolated contributors along the central cross-section $A A^{\prime}$. 


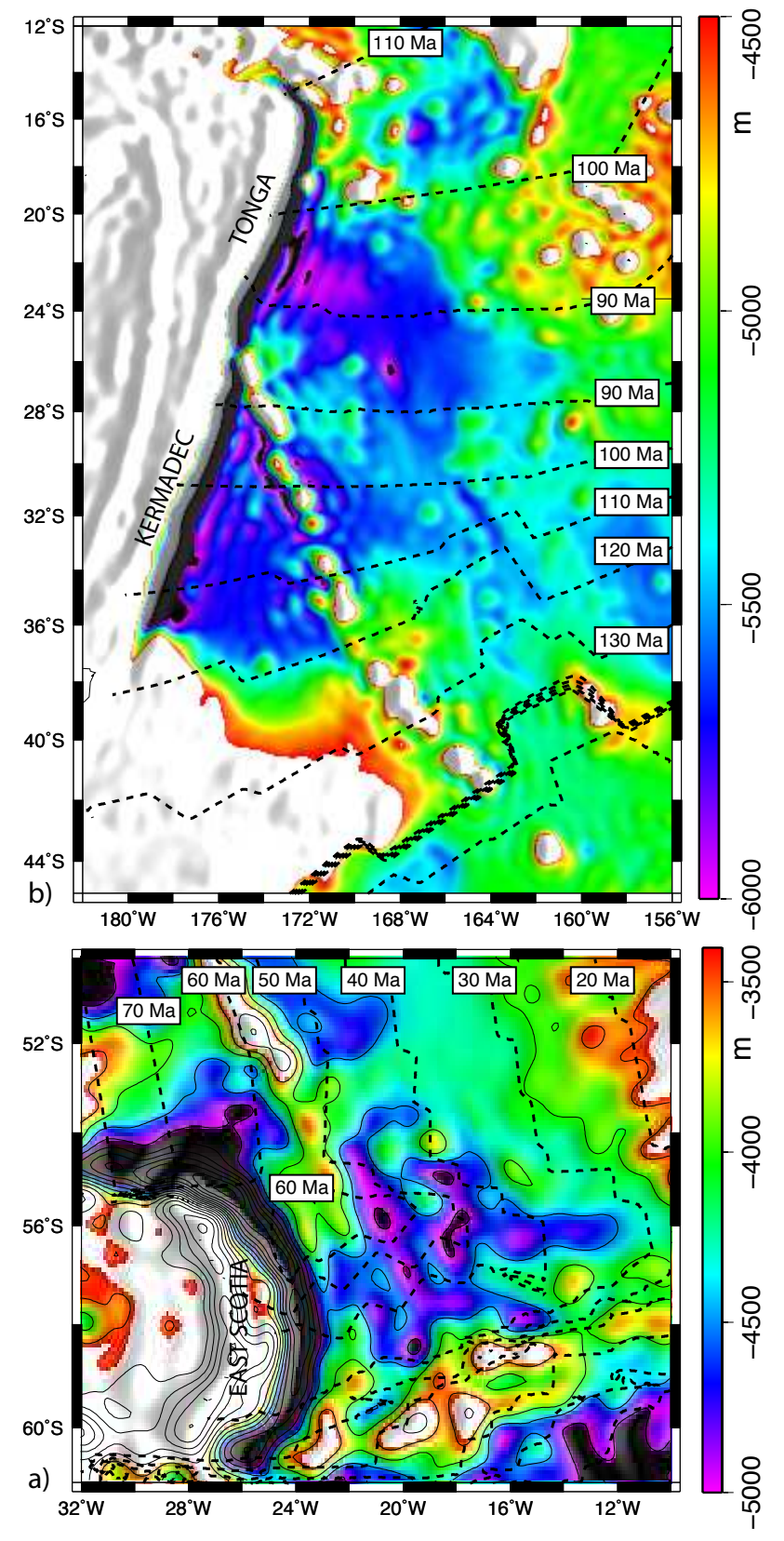

Fig. 6. Bathymetry on the foresides of the East Scotia (a) and Tonga and Kermadec (b) subduction zones. Wavelengths shorter than $100 \mathrm{~km}$ have been filtered out. Note the low lying areas on the foresides of each trench, 5000 m deep (East Scotia), $\sim 6000 \mathrm{~m}$ deep (Tonga) and $\sim 5700 \mathrm{~m}$ deep (Kermadec). In all three cases, they are 800 to $1000 \mathrm{~m}$ deeper than the adjacent seafloor of similar age. Seafloor age from [54]. 


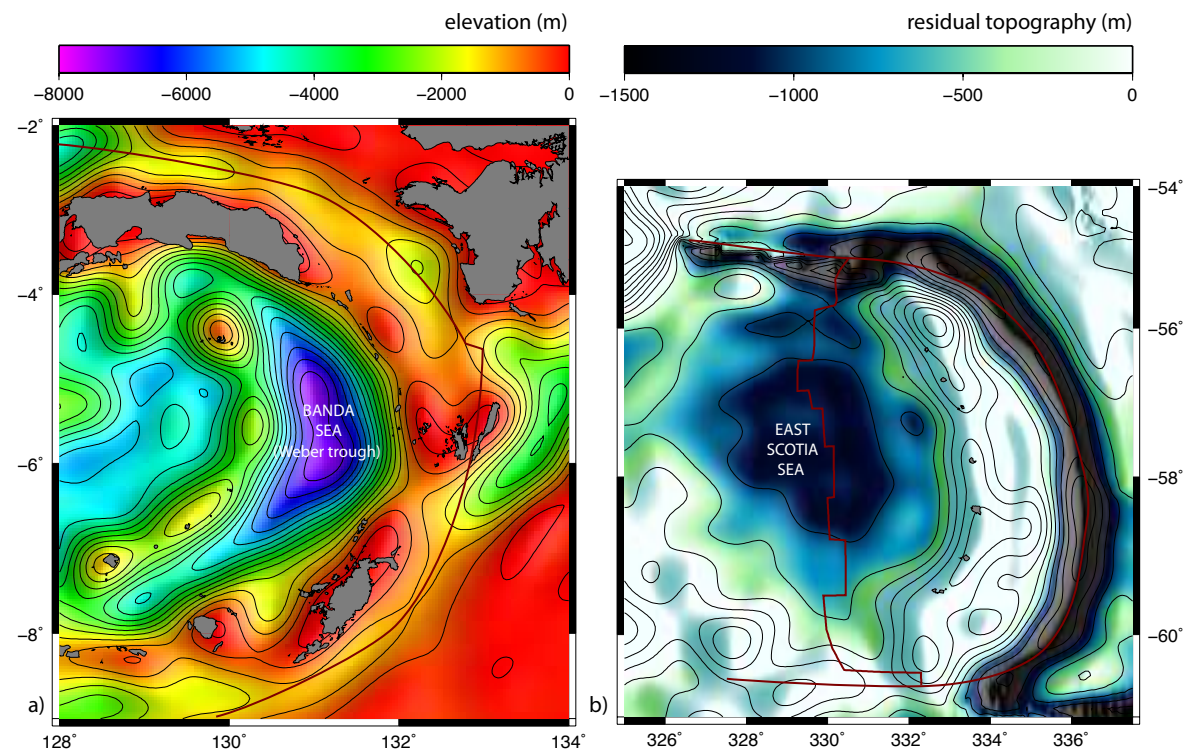

Fig. 7. Bathymetry on the backside of the Banda subduction zone (a) and residual bathymetry of the East Scotia subduction zone (b, modified after [5]). (Residual topography of the extremely young Banda back-arc basin was not computed (unavailable seafloor age grid) but is expected to be almost comparable to the residual topography). Wavelengths shorter than $100 \mathrm{~km}$ have been filtered out. Note the $\sim 8000 \mathrm{~m}$ deep Weber trough on the backside of Banda trench, and the $\sim 1500 \mathrm{~m}$ residual topography in the East Scotia back arc basin. 


\section{Supplementary material 1.}

Experimental parameters. ( $W$ : plate width; $H$ : plate thickness; $D$ : mantle thickness $\rho_{l}$ : plate density; $\eta_{l}$ : plate viscosity; $\rho_{m}$ : mantle density; $\eta_{m}$ : mantle viscosity; $\rho_{l l}$ : light plate density).

\begin{tabular}{ccccccccccc} 
Model & $W$ & $H$ & $D$ & $\rho_{l}$ & $\eta_{l}$ & $\rho_{m}$ & $\eta_{m}$ & $\rho_{l l}$ & $\eta_{l} / \eta_{m}$ & $\rho_{l}-\rho_{m}$ \\
& $m m$ & $m m$ & $m m$ & $\mathrm{~kg} / \mathrm{m}^{3}$ & $P a s$ & $\mathrm{~kg} / \mathrm{m}^{3}$ & $P a s$ & $\mathrm{~kg} / \mathrm{m}^{3}$ & & $\mathrm{~kg} / \mathrm{m}^{3}$ \\
\hline 1 & 150 & 15.2 & 100 & 1506 & $4.2 \times 10^{5}$ & 1415 & 30 & - & 14000 & 91 \\
2 & 200 & 13.7 & 100 & 1468 & $3.0 \times 10^{5}$ & 1415 & 30 & - & 10000 & 53 \\
3 & 150 & 12.5 & 100 & 1468 & $3.0 \times 10^{5}$ & 1415 & 30 & - & 10000 & 53 \\
4 & 200 & 13.0 & 100 & 1506 & $4.2 \times 10^{5}$ & 1415 & 30 & - & 14000 & 91 \\
5 & 200 & 15.5 & 100 & 1506 & $4.2 \times 10^{5}$ & 1415 & 30 & - & 14000 & 91 \\
6 & 150 & 13.7 & 100 & 1506 & $4.2 \times 10^{5}$ & 1415 & 30 & - & 14000 & 91 \\
7 & 145 & 15.5 & 100 & 1468 & $3.0 \times 10^{5}$ & 1415 & 30 & - & 10000 & 53 \\
8 & 150 & 15.0 & 97 & 1506 & $4.2 \times 10^{5}$ & 1450 & 1000 & - & 420 & 56 \\
9 & 200 & 15.0 & 100 & 1506 & $4.2 \times 10^{5}$ & 1450 & 1000 & - & 420 & 56 \\
10 & 200 & 12.8 & 98 & 1506 & $4.2 \times 10^{5}$ & 1450 & 1000 & - & 420 & 56 \\
11 & 150 & 13.0 & 95 & 1506 & $4.2 \times 10^{5}$ & 1450 & 1000 & - & 420 & 56 \\
12 & 150 & 12.0 & 100 & 1506 & $4.2 \times 10^{5}$ & 1450 & 1000 & 1458 & 420 & 56 \\
13 & 150 & 12.0 & 100 & 1506 & $4.2 \times 10^{5}$ & 1450 & 1000 & 1458 & 420 & 56
\end{tabular}

